论 文

\title{
青藏高原冰川雪冰中多环芳烃的分布特征及其 来源研究
}

\author{
李全莲 ${ }^{*}$, 王宁练, 武小波, 蒲健辰, 贺建桥, 张春文 \\ 中国科学院寒区早区环境与工程研究所, 冰冻圈科学国家重点实验室, 兰州 730000 \\ *E-mail: liql@1zb.ac.cn \\ 收稿日期: 2009-01-14; 接受日期: 2010-04-13 \\ 国家自然科学基金(批准号: 40801023, 40930526, 40871038)和西部博士资助项目(编号: 290928601)资助
}

\begin{abstract}
摘要在青藏高原的祁连山七一冰川、东昆仑山玉珠峰冰川、唐古拉山小冬克玛底冰川和 念青唐古拉山羊八井地区古仁河口冰川总共收集了 20 个雪冰样品, 利用 GC-MS 分析了 16 个 优控多环芳烃的含量和分布特征, 并探讨了它们的来源. 结果表明, 这 4 条冰川雪冰中多环芳 烃的含量范围在 20.45 60.57 ng/L 之间, 玉珠峰冰川中最高, 小冬克玛底冰川中最低, 没有表 现出明显的区域规律. 雪冰中的多环芳烃主要以 2 4 环低分子量的化合物为主, 以菲的含量 最高. 结合因子分析和多环芳烃的相关参数分析结果, 说明青藏高原地区冰川中的多环芳烃 主要来自煤和生物质的低温燃烧, 机车尾气也贡献了一部分多环芳烃. 通过气团轨迹示意图 发现, 这四条冰川雪坑所代表时段内雪冰中的有机污染物主要源自西风环流途径的中亚及中 国西北干旱区.
\end{abstract}

关键词

青藏高原

雪冰

多环芳烃

物质来源
多环芳烃(Polycyclic Aromatic Hydrocarbons, PAHs) 是指两个或两个以上的苯环以稠环形式相连 的化合物, 是一类广泛存在于环境中的持久性有机 污染物(Persistent Organic Pollutants, POPs), 具有较 强的致癌、致畸和致突变性 ${ }^{[1]}$. 美国环保局已将 16 种多环芳烃列入优先控制的有毒有机污染物黑名单 中 $^{[2,3]}$. 多环芳烃主要有两个来源 ${ }^{[4,5]}$ : 天然源和人为 源. 天然源主要包括森林植被和灌木丛的天然火灾 以及火山喷发、高等植物和微生物的合成以及有机质 成岩过程中产生的多环芳烃. 人为源主要包括化石 燃料(煤和石油)、生物燃料等的不完全然烧和机动车 尾气的排放, 以及石油开发、运输和石油化工过程的 泄露与排放. 与自然源相比, 人为源是多环芳烃的主
要产生源 ${ }^{[6]}$. 多苯环共轭体系使该类化合物具有高度 的稳定性, 难以降解, 因此多环芳烃被认为是人类活 动的良好指示剂 ${ }^{[7]}$, 其含量与区域能源消耗、工业化 水平以及城市化进程有着很好的相关性 ${ }^{[8]}$. 由于其具 有很强的迁移能力和持久性, 此类污染物可以通过 不同的作用方式在不同的介质间转化, 并通过大气 传输和运移在区域内甚至全球范围内分布 ${ }^{[9]}$.

国内外已经研究了气溶胶 ${ }^{[10]}$ 、河流、湖泊沉积 物 $^{[11,12]}$ 、植被 ${ }^{[13]}$ 、土壤 ${ }^{[14]}$ 等介质中多环芳烃的组成和 分布特征、污染来源以及沉积机理等, 这些介质都可 以反映大气中多环芳烃的变化. 研究表明, 降雪能有 效地从空气中清除气态和颗粒负载的多环芳烃 ${ }^{[15]}$, 因此, 冰川是记录大气中多环芳烃的重要载体. 冰川

引用格式: Li Q L, Wang N L, Wu X B, et al. Sources and distribution of polycyclic aromatic hydrocarbons of different glaciers over the Tibetan Plateau. Sci China Earth Sci, 2010, doi: 10.1007/s11430-010-4047-3 
中的有机污染物随冰川融水直接汇入汇、河、湖泊等 地表水体中，对人类的饮用水源和农田供给水资源 造成潜在的影响. 因此, 研究冰川中有机污染物的含 量水平对于评价该类污染物对人类和动物健康以及 其他生态系统的危害具有重要意义 ${ }^{[16]}$. 目前对于冰 川中多环芳烃的研究主要集中在阿尔卑斯山 ${ }^{[17]}$ 和两 极地区 ${ }^{[18,19]}$, 青藏高原地区的冰川少有研究, 而且对 雪冰中多环芳烃仅有的研究也主要是针对季节性变 化, 缺乏区域之间的对比. 为了充分认识高原不同地 区雪冰中有机物组成和含量的区域特征, 我们在祁 连山七一冰川、东昆仑山玉珠峰冰川、唐古拉山小冬 克玛底冰川以及念青唐古拉山羊八井地区古仁河口 冰川采集雪坑样品, 对这几条冰川中的多环芳烃进 行了定量分析, 研究了它们的组成以及空间分布规 律, 并根据多环芳烃的组成和参数特征对青藏高原 冰川中多环芳烃的来源进行了初步探讨.

\section{1 实验}

\section{1 采样位置}

在青藏高原从南向北选择古仁河口冰川(GRHK), 小冬克玛底冰川(XDKMD), 玉珠峰冰川(YZF)和七 一冰川 $(\mathrm{QY})$ 采集雪样进行多环芳烃研究, 这 4 条冰川 所在的地区覆盖了不同的气候和植被区域, 气候表 现出从南部地区相对温暖湿润的状态, 向北部地区 寒冷半干旱、干旱的气候状态过渡; 植被分布也基本 呈现南部地区植被覆盖好, 逐渐向北部地区减少的 特征. 七一冰川 $\left(39^{\circ} 14^{\prime} 19^{\prime \prime} \mathrm{N}, 97^{\circ} 45^{\prime} 43^{\prime \prime} \mathrm{E}\right)$ 位于青藏高 原东北边缘的祁连山中部, 祁连山中东段都有森林、 草原、灌丛、草甸发育，具有干旱荒漠区边缘“湿岛” 的特征. 玉珠峰冰川 $\left(35^{\circ} 39^{\prime} 37^{\prime \prime} \mathrm{N}, 94^{\circ} 14^{\prime} 28^{\prime \prime} \mathrm{E}\right)$ 位于高 原北部的东昆仑山地区, 海拔高, 气候寒冷、干旱、 森林覆盖率低, 该区监测到的厥类植物都是陆生类 型, 缺乏附生类型和水生类型. 小冬克玛底冰川 $\left(33^{\circ} 4^{\prime} 18^{\prime \prime} \mathrm{N}, 94^{\circ} 14^{\prime} 01^{\prime \prime} \mathrm{E}\right)$ 位于青藏高原腹地唐古拉山 脉北坡, 植被以高寒草原为主. 古仁河口冰川 $\left(30^{\circ} 03^{\prime} 54^{\prime \prime} \mathrm{N}, 90^{\circ} 29^{\prime} 34^{\prime \prime} \mathrm{E}\right)$ 位于羊八井附近, 降水量比 高原北部地区多.

\section{2 样品采集}

2008 年 5 月 18 日、 5 月 26 日、 6 月 2 日分别在 东昆仑山的玉珠峰冰川(海拔 $5610 \mathrm{~m}$ )、唐古拉山小冬
克玛底冰川(海拔 $5670 \mathrm{~m}$ )、念青唐古拉山羊八井地区 古仁河口冰川(海拔 $4520 \mathrm{~m}$ )挖取 $40 \mathrm{~cm}$ 深的雪坑. 从 上往下每隔 $8 \mathrm{~cm}$ 采集 1 个样品, 每个雪坑总共采集 5 个样品用于有机物分析. 2008 年 6 月 21 日, 在祁连山 七一冰川挖取 $17.5 \mathrm{~cm}$ 深的雪坑(海拔 $4800 \mathrm{~m}$ ), 根据 自然层理取样 4 个, 并在海拔 $4473 \mathrm{~m}$ 处采集表层雪 样 1 个. 各冰川的雪样都采于积累区, 每个点的样品 都是一次性取完, 样品的融水体积在 7.6 17.9 L 之间. 雪坑样品的取样位置见图 1 .

\section{3 试剂和材料}

选用不锈钢铲采集雪样, 每个样品分 4 份分装在 容积为 $12 \mathrm{~L}$ 的搪瓷水桶或不锈钢水桶中. 试验中所 用到的玻璃仪器、采样工具以及盛装雪样的搪瓷水桶 和不锈钢水桶在使用前都用洗液反复浸泡并用超纯 水清洗多遍. 大孔吸附树脂(G.D.X-102 和 G.D.X-105 的 1:1 均匀混合物)在索氏抽提器中用甲醇和二氯甲 烷分别抽提 $96 \mathrm{~h}$, 最后保存在甲醇中备用. 滤纸和脱 脂棉也经甲醇和二氯甲烷分别抽提 $48 \mathrm{~h}$ 后真空抽干 保存. 硅胶和三氧化二铝使用前分别在 180 和 $250^{\circ} \mathrm{C}$ 活化 $5 \mathrm{~h}$, 无水硫酸钠使用前在马弗炉中 $450^{\circ} \mathrm{C}$ 活化 $24 \mathrm{~h}$. 本实验所用到的溶剂 (甲醇、二氯甲烷和正己烷) 均为从德国 Merck公司购买的农残级试剂. 多环芳烃 标样包括芸(Nap)、范(Any)、二氢苊(Ane)、芴(Fle)、 菲 $(\mathrm{Phe})$ 、葱 $(\mathrm{Ant}) 、$ 苂葱 $(\mathrm{Fla}) 、$ 芘 $(\mathrm{Pyr})$ 、苯并 $[\mathrm{a}]$ 蒽 $(B(a) A) 、$ 屈 $(C h r y) 、$ 苯并 $[b]$ 荧葱 $(B(b) F) 、$ 苯并 $[k]$ 荧 蒽 $(B(k) F) 、$ 苯并 $[a]$ 萠 $(B(a) P) 、 二$ 苯并 $[a, h]$ 蒽 $(D a A) 、$ 狮并[1,2, 3-cd]萠(INP)、苯并 [ghi]荘(B(ghi)P)共 16 种 化合物购自美国 Supelco 公司.

\section{4 样品前处理过程}

所有雪冰样品在密封的搪瓷水桶或不锈钢水桶 中自然融化(需 1 2 天不等), 用优级纯浓盐酸调整 $\mathrm{pH}$ 值至 2 左右, 在野外富集. 采用湿法装柱, 将甲醇-树 脂浆状转移到层析柱中, 上样前依次用二氯甲烷和 甲醇洗涤树脂柱，然后用超纯水分几次冲洗，最后让 冰雪融水缓慢通过吸附柱，树脂吸附柱床高约 8 9 $\mathrm{cm}$, 上下两端塞有脱脂棉. 待吸附完毕后, 用洗耳球 将树脂中残留的水压出, 用已经高温烘烤过的锡篞 纸包好吸附柱, 低温保存, 带回中国科学院寒区旱区 环境与工程研究所实验室.

在超净化室内用 $30 \mathrm{~mL}$ 二氯甲烷分三次洗脱树 


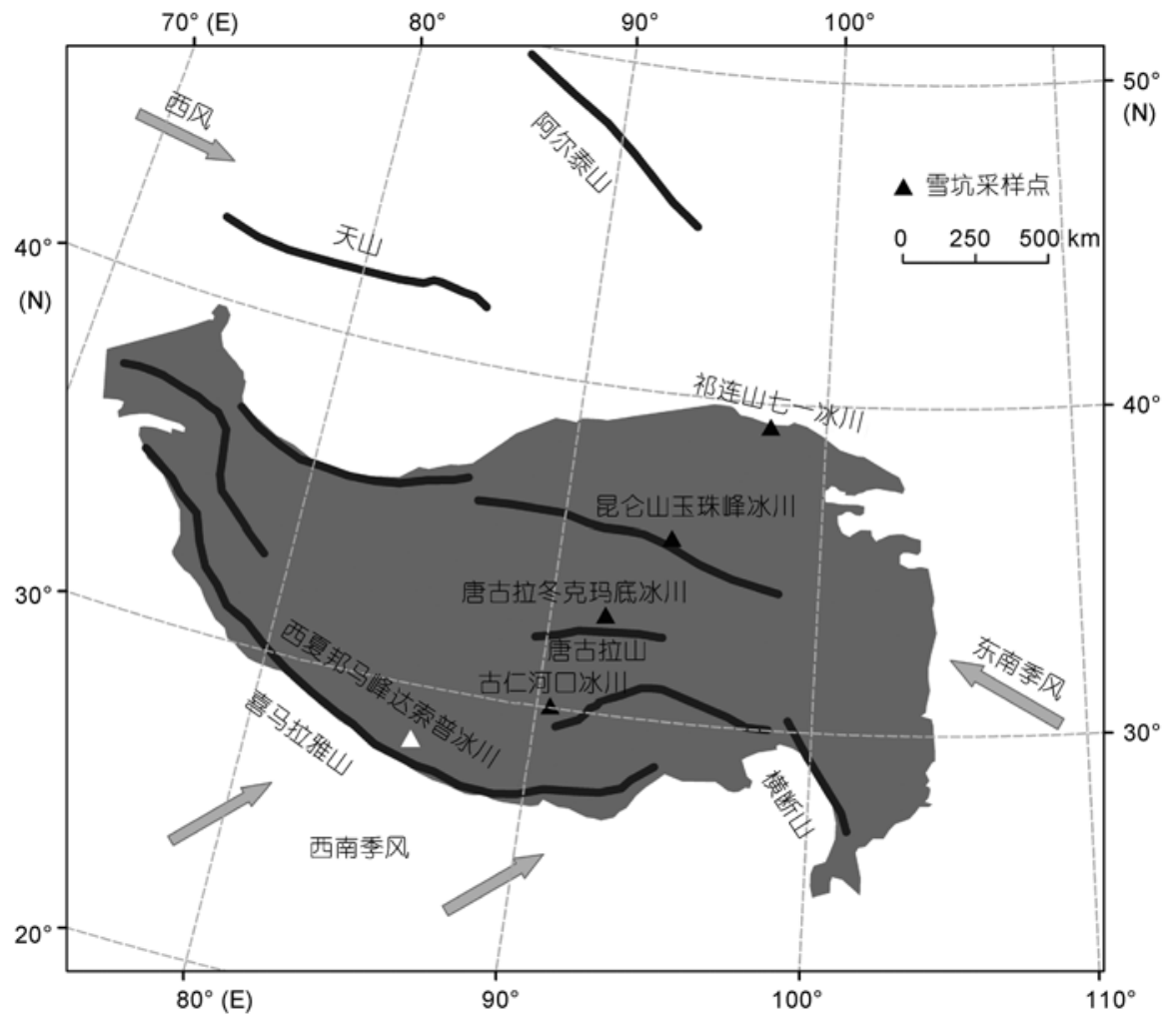

图 1 雪坑采样点的位置图

脂柱, 每次洗脱时让溶剂在柱中平衡 $5 \mathrm{~h}$, 洗脱完毕 后, 自然挥发溶剂至干, 衡重, 然后过无水硫酸钠、 硅胶和氧化铝的层析柱进行干燥和族组份分离. 用 正己烷与二氯甲烷的混合物 (1:3)洗脱出多环芳烃, 挥发至干, 然后定容至 $2 \mathrm{~mL}$, 上气相色谱-质谱联用 仪. 空白样品是将超纯水用不锈钢桶带到野外, 处理 程序与样品相同, 每个冰川做一个空白. 野外空白实 验表明, 主要的污染物是邻苯二甲酸酯类物质, 不影 响待测化合物的定性和定量.

\section{5 样品质量控制与质量保证和分析条件}

样品分析在中国科学院青藏高原研究所完成. 所用仪器为美国 Thermo Finnigan 公司离子阱气质联 用仪 GC-MS (Finnigan Trace GC/PolarisQ), 配有 Triplus 自动进样器, DB-5MS 毛细管柱 $(30 \mathrm{~m} \times 0.25$ $\mathrm{mm} \times 0.25 \mu \mathrm{m})$. 气相色谱的升温程序为: 在 $50^{\circ} \mathrm{C}$ 保持 $2 \mathrm{~min}$, 以 $20^{\circ} \mathrm{C} / \mathrm{min}$ 升温到 $180^{\circ} \mathrm{C}$; 再以 $4^{\circ} \mathrm{C} / \mathrm{min}$ 的速 度升至 $250{ }^{\circ} \mathrm{C} ; 2^{\circ} \mathrm{C} / \mathrm{min}$ 升温到 $280^{\circ} \mathrm{C}$; 最后以 $10^{\circ} \mathrm{C} / \mathrm{min}$ 升温到 $310^{\circ} \mathrm{C}$, 保持 $5 \mathrm{~min}$. 使用 16 种优控 多环芳烃的混合溶液作为标准参考物质定量.

\section{2 结果与讨论}

\section{1 不同冰川雪冰中 PAHs 的含量和分布特征}

图 2 显示了七一冰川、玉珠峰冰川、小冬克玛底 冰川和古仁河口冰川雪冰中 16 种优控多环芳烃总含 量的平均值. 其中玉珠峰冰川含量最高, 平均值是 $60.57 \mathrm{ng} / \mathrm{L}$; 七一冰川次之, 平均值是 $31.19 \mathrm{ng} / \mathrm{L}$; 然 后是古仁河口冰川, 平均值是 $24.59 \mathrm{ng} / \mathrm{L}$; 小冬克玛 底冰川含量最低, 平均值是 $20.45 \mathrm{ng} / \mathrm{L}$. 已有的研究 表明, 欧洲高山地区雪中 3 7 环多环芳烃的浓度之和 是 $5.6 \sim 81 \mathrm{ng} / \mathrm{L}^{[17]}$, 与我们研究的 4 条冰川接近, 而高 于东南极冰盖中痕量多环芳烃的浓度 $(10 \mathrm{ng} / \mathrm{L})^{[18]}$, 这可能是因为高山地区相比极地离多环芳烃源区更 近的缘故 ${ }^{[20]}$. 青藏高原达索普冰川冰芯中多环芳烃 (二氢范、想、菲、苂葱和芘)的浓度之和是 8.9 97 ng/L, 平均值为 $26 \mathrm{ng} / \mathrm{L}^{[21]}$, 东线布冰川冰芯中多环芳烃的 平均浓度都低于 $100 \mathrm{ng} / \mathrm{L}^{[22]}$, 这两条冰川都处于高原 南部, 根据气团示踪发现, 这里的多环芳烃可能来自 印度. 青藏高原地区几条冰川中的多环芳烃含量没 有表现出明显的区域规律, 可能是由于时空差别所 
致, 反映了全球多环芳烃排放随时间变化和在不同 区域的使用模式. 但是总体而言, 青藏高原冰川雪冰 中多环芳烃的含量要远低于珠穆朗玛峰地区 ${ }^{[23]}$ 土壤 $(168 \sim 595 \mathrm{ng} / \mathrm{g})$ 和柔籽草(12.8 92.5 ng/g) 以及棘豆 $(49.4 \sim 14.6 \mathrm{ng} / \mathrm{g})$ 几个数量级, 这与多环芳烃易被植被 中的脂类和土壤中的有机质吸附有关.

如图 3 可知, 4 条冰川雪冰样品中都未检测到二 苯并葱, 而且单个多环芳烃的组份有所不同, 但都以 菲的含量最高. 古仁河口冰川和小冬克玛底冰川以 二氢范为次主要化合物, 玉珠峰冰川和七一冰川以 荧葱为次主要化合物, 玉珠峰冰川中芴的含量比其 他三条冰川都高. 如图 4 所示, 七一冰川、玉珠峰冰 川、小冬克玛底冰川和古仁河口冰川中 2 4 环多环芳 烃的平均含量占总多环芳烃的百份含量分别是 $88 \%$, 98.75\%, 94.34\% 和 $95.95 \%$. 结合达索普冰川与东线 布冰川也以 2 4环多环芳烃为主的分布特征, 说明在 青藏高原冰川雪冰中检测到的多环芳烃都以低分子 量化合物为主. 这种分布特征与加拿大北极的褐色 雪事件 ${ }^{[24]}$ 和格陵兰冰盖类似 ${ }^{[25-26]}$, 但是与气溶胶 ${ }^{[27]}$ 和沉积物 ${ }^{[28]}$ 相反, 后者主要以苂葱和萠为主, 高分子 量的多环芳烃占了较大比例.

大量事实证明, 长距离大气传输和干湿沉降是 高海拔地区输入POPs的主要途径 ${ }^{[29]}$. 多环芳烃是半 挥发性有机污染物, 以气态和颗粒态两种形式存在 于大气中. 其中, 分子量较小的多环芳烃(<202)主要 以气态形式存在, 而分子量较大 $(>202)$ 的多环芳烃则 倾向于以颗粒态形式出现 ${ }^{[30]}$. Daly和Wania ${ }^{[31]}$ 研究证 明, 半挥发性有机化合物的分布特征主要取决于它 们的物理化学性质以及这些地区的环境和气候

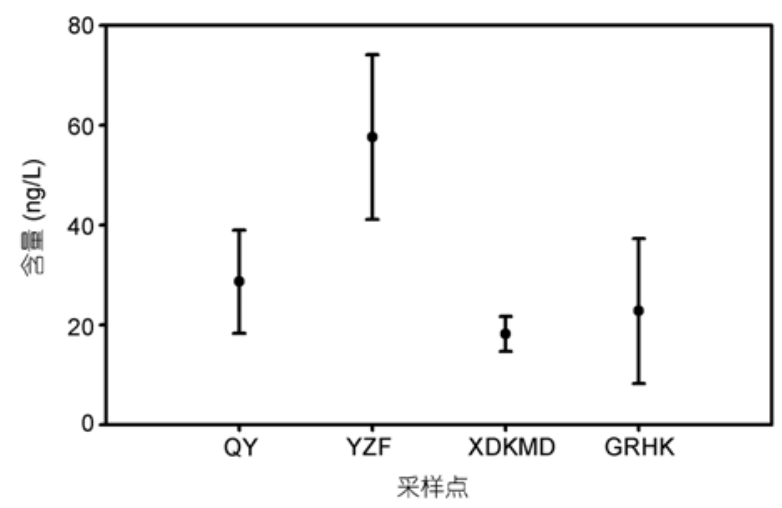

图 2 不同采样点 PAHs 的总含量
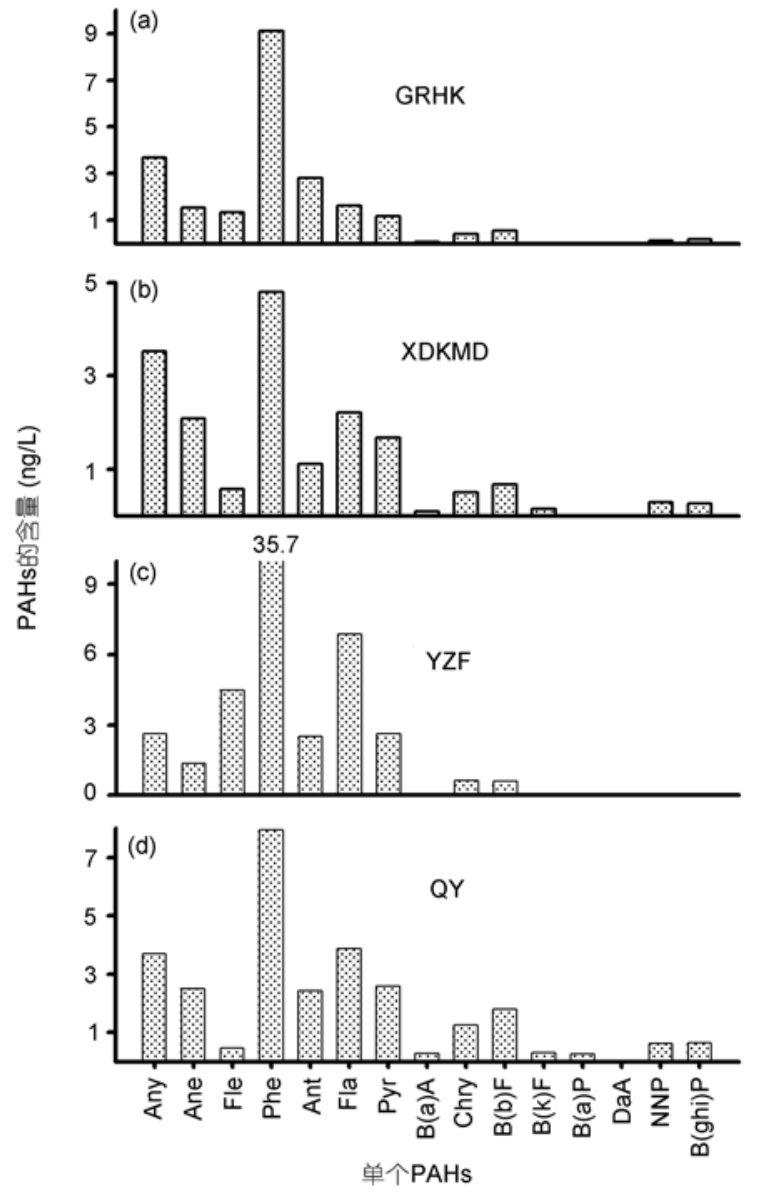

图 3 不同冰川中单个多环芳烃的平均含量

条件. 青藏高原冰川雪冰中多环芳烃的组成与偏远 地区类似, 以低分子量化合物为主, 主要原因是由于 它们离源区较远. 而与气溶胶、沉积物的差别则主要 是由于不同分子量的多环芳烃在物理化学性质和传 输机制上(即大气蒝汽压)有很大的差异, 引起轻重多 环芳烃组分在传输过程中分馏. 排放到大气中的多 环芳烃, 由于它们在大气迁移过程中发生组成分异, 分子量较低的多环芳烃因为挥发性较好, 迁移距离 更远，更趋向于向高海拔或高纬度地区富集，温度降 低后, 它们迅速冷凝或被具有高度吸附性能的细小 尘埃所吸附，然后被降雪捕获进入冰川。高分子量的 多环芳烃，如 5 环和 6 环的苯并 $[\mathrm{b}]$ 苂葸、苯并 $[\mathrm{k}]$ 苂葱、 苯并 $[\mathrm{a}]$ 萠、二苯并 $[\mathrm{a}, \mathrm{h}]$ 葸、苯并 $[\mathrm{ghi}]$ 萠和狮并 [1,2,3-cd] 萠, 它们则更倾向于吸附在大气颗粒物上 进行迁移, 在到达高海拔地区之前会优先沉积 ${ }^{[32,33]}$, 一旦从大气中沉积, 它们往往储存在土壤-水-植物系 


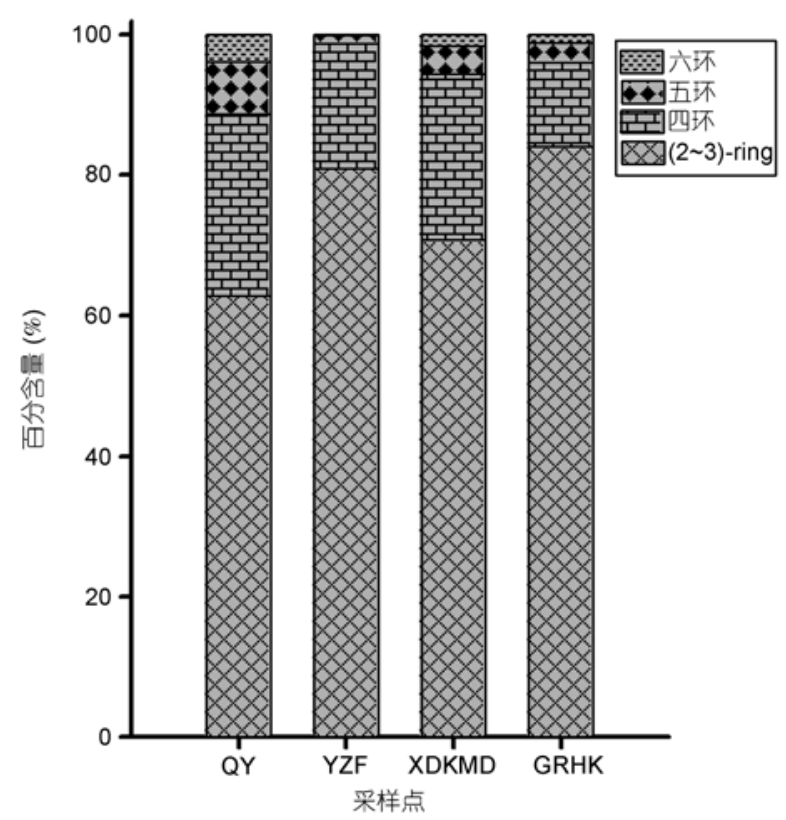

图 4 不同冰川中不同环数多环芳烃的百分含量 三环多环芳烃包括二氢范、范、芴、菲和葱, 四环包括苂蒌、芘、 苯并 $[a]$ 葱和屈, 五环包括苯并 $[\mathrm{b}]$ 苂葱、苯并 $[k]$ 苂葱、苯并 $[\mathrm{a}]$ 萠和二 苯并 $[a, h]$ 葸, 六环包括狮并萠和苯并(ghi) 菲

统 $^{[34]}$, 而不是迁移到高海拔地区. 另外, 轻重组分的 相对百分含量可能也与采样地点的气候、环流特征、 海拔高度以及粉尘的含量和来源等诸多因素有关.

\subsection{PAHs 的来源}

\subsection{1 比值法}

人为源中, 多环芳烃及其衍生物主要是由化石 燃料(煤和石油)、机动车辆尾气排放以及木材、塑料

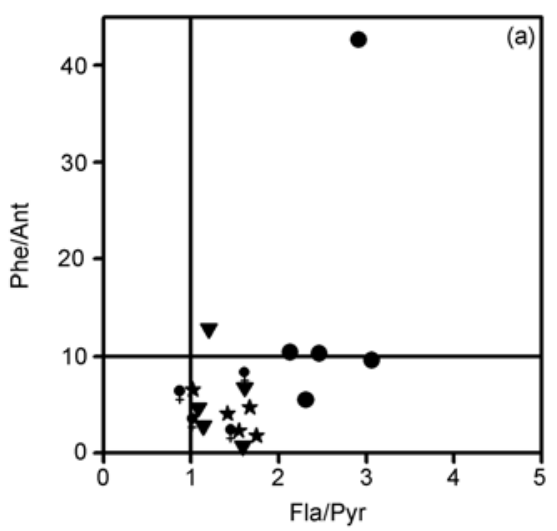

经不完全燃烧或在还原性气氛中热分解形成的. 许 多学者利用相同分子量和相似结构多环芳烃之间的 比值来识别污染源. Guinan等 ${ }^{[35]}$ 用菲/蒽(Phe/Ant)和 荧蒽/萠(Fla/Pyr)的比值来判定多环芳烃的来源, 用 以区分原油污染和不完全燃烧热解源的多环芳烃. 认为燃烧产生的多环芳烃Phe/Ant小于 10, 而Fla/Pyr 大于 1 , 而且 Fla/Pyr比值接近于 1.4 为煤燃烧源, Fla/Pyr比值接近于 1 , 来自木材的燃烧 ${ }^{[36]}$; 油成因来 源的多环芳烃Phe/Ant大于 10 , 而Fla/Pyr 小于 1 . 根据 Yunker等 ${ }^{[37]}$ 归纳的结果, Fla/(Pyr+Fla) 比值小于 0.4 则 意味着石油污染来源, 大于 0.5 则主要是木材、煤燃 烧来源, 位于 $0.4 ~ 0.5$ 之间则意味着石油及其精炼产 品的燃烧来源; Ant/(Phe+Ant) 比值小于 0.1 时, 主要 是石油类污染, 大于 0.1 时以不完全燃烧产物为主. 由图 5 可见, 玉珠峰冰川大部分雪样以及小冬克玛底 冰川个别雪样中Phe/Ant大于 $10, \mathrm{Ant} /(\mathrm{Phe}+\mathrm{Ant})$ 比值 小于 0.1 时, 说明玉珠峰冰川可能受到了石油污染(玉 珠峰冰川雪样中正构烷烃的CPI值接近于 1 也证实了 这一点 $\left.{ }^{[38]}\right)$. 其他雪样中, Phe/Ant范围在 $0.73 \sim 12.87$, 平均值小于 $10, \mathrm{Fla} / \mathrm{Pyr}$ 范围在 $0.87 \sim 1.75$, 平均值大于 1, Ant/(Phe+Ant) 范围在 0.07 0.58, 比值大于 0.1 , $\mathrm{Fla} /(\mathrm{Pyr}+\mathrm{Fla})$ 范围在 0.47 0.64, 平均值大于 0.4 , 通过 以上比值可初步判断除玉珠峰冰川受到了石油污染, 其他 3 条冰川中的多环芳烃主要来自化石燃料的不 完全燃烧.

\subsection{2 因子分析法}

由于多环芳烃种类繁多，且不同化合物在形态、 物理化学性质上均存在较大的差异. 本研究也对除

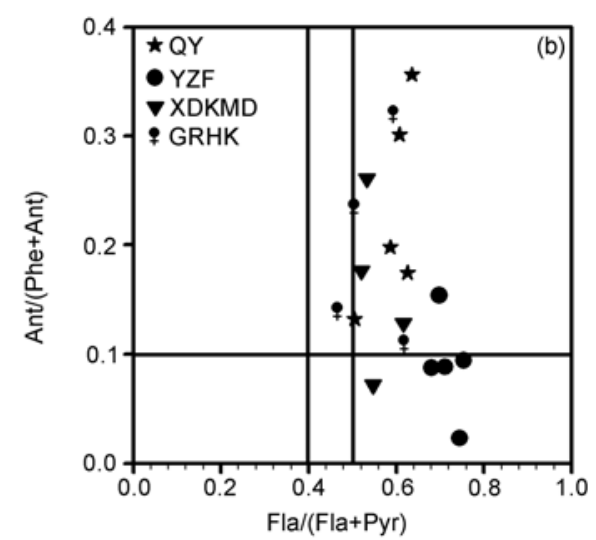

图 5 Phe/Ant 与 Fla/Pyr 和 Ant/(Ant+Phe)与 Fla/(Fla+Pyr)的交叉图 


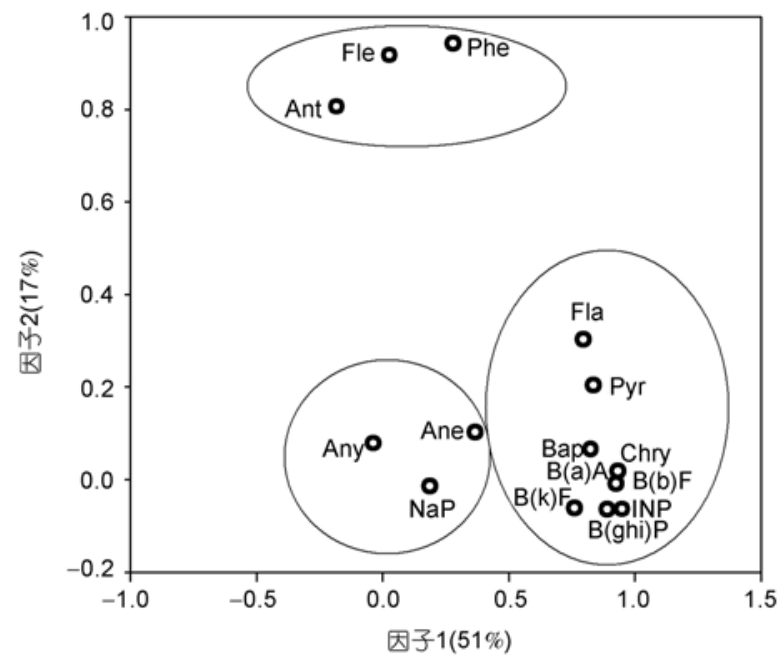

图 6 青藏高原冰川中 PAHs 的因子载荷

玉珠峰冰川以外的三条冰川进行了主成分分析 (Principal Component Analysis, PCA). 因为二苯并[a] 葱的含量低于仪器的检测限, 故只对这三条冰川中 的 15 个多环芳烃进行了因子分析. 根据特征值大于 1 的提取原则, 得出 2 个主因子, 分别解释了总变量 的 $50.82 \%$ 和 $17.25 \%$, 并利用方差最大Varimax正交 因子旋转法进行了因子旋转, 结果如图 6. 由图 6 可 见, 15 个变量可分为 3 组, 右下角一组在变量菼葱、 萠、苯并 $[a]$ 蕊、屈、苯并 $[a]$ 萠、苯并 $[b]$ 苂葱、苯并 $[\mathrm{k}]$ 苂菤、狮并 $[1,2,3-\mathrm{cd}]$ 萠和苯并 [ghi]芢等化合物上有 很高的载荷系数, 它们均是高分子量和高环数的多 环芳烃. 其中, 苯并 $[\mathrm{k}]$ 荧葱、狮并 $[1,2,3-\mathrm{cd}]$ 萠和苯并 [ghi]菲等是作为机动车尾气排放的特征标志物, 已 被众多的研究所证实 ${ }^{[39]}$. 苂葱和萠主要来自于煤和 石油的燃烧产生 ${ }^{[40]}$. 因此, 我们认为因子 1 代表了煤 和石油的燃烧以及机动车尾气排放的混合源. 上面 一组包括菲、芴和葱, 它们都是三环的多环芳烃. 其 中菲的载荷系数最高, 其次为芴和葱. 菲和芴被认为 主要是来自生物质和煤的低温燃烧产生 ${ }^{[41]}$. Mastral ${ }^{[42]}$ 研究表明, 荡是不同条件下煤燃烧时排放出多环芳 烃中含量最高的化合物. Khalili等 ${ }^{\left[{ }^{[3]}\right.}$ 也通过实验证实, 芝加哥炼焦炉排放的多环芳烃中芴和其他轻组分化 合物占优势. Simcik等 ${ }^{[44]}$ 也将芴和葱视为焦炉燃烧源 的因子特征. 由此可见, 因子 2 主要体现了生物质和 煤的低温燃烧产生多环芳烃的排放特征. 左下角一 组二氢苊、荎和苊的载荷系数都很高, 这三种低环数 化合物有很高的蒸汽压, 在大气中呈气态形式存在,
主要以气-雪界面交换的方式大量进入冰川, 并主要 以溶解相形式存在，因此，气-雪界面交换作用可能 是导致冰川中二氢苊、荥和苊含量较高的主要原因. 二氢范和范也被认为是指示机动车排放的特征化合 物之一 ${ }^{[43]}$.

综合比值法和因子分析法判断青藏高原冰川中 的多环芳烃主要来自煤和化石燃料的低温燃烧. 青 藏高原地处中低纬度高海拔地区, 平均海拔超过 $4000 \mathrm{~m}$, 是全球最高最大的高原, 受季风、地中海、 印度洋、孟加拉湾工业区长途传输气团的影响. 加之 我国是一个以煤炭资源为主要能源的国家, 尤其在 我国北方, 燃煤是空气中多环芳烃的重要污染源. 另 外, 人口的剧烈增长, 机动车使用的增加都会导致多 环芳烃增加, 这些排放到空气中的多环芳烃都会随 着季风的传输而到达青藏高原.

\section{3 气团轨迹示踪}

为了追踪这 4 条冰川雪坑样品代表时段内的水 汽来源, 利用美国NOAA气象资料提供的HYSLPIT4 气团轨迹模型结合 FNL气象数据库(http://www.arl. noaa.gov/ready/open/hysplit4.html), 通过反向轨迹模 式计算到达这 4 条冰川的气团运动轨迹. 图 7 显示的 是古仁河口冰川、小冬克玛底冰川、玉珠峰冰川和七 一冰川雪坑代表时段内不同气团的运动轨迹. 如图 7 中 GRHK-A D所示, 古仁河口冰川 6 月和 3 月主要受 西风环流所携带的中亚及我国西北干旱区粉尘的影 响, 而 4 5 月主要受南亚季风环流携带的印度次大陆 的大气污染物的影响. 田立德等 ${ }^{[45]}$ 研究指出, 唐古拉 山南北不同性质气团的差异造成该区南北两侧水汽 来源不同. 唐古拉山以北水汽主要源自内陆, 而以南 则源自海洋. 由于古仁河口冰川位于高原中南部, 而 且其雪冰样品采集于 2008 年 6 月初, 因此可以推断 该冰川中检测到的有机污染物来自中亚及我国西北 干旱区. 图 7 中XDKMD-A D显示唐古拉小冬克玛底 冰川既受到了内陆局地水汽的影响, 也受到了少量 西南季风带来的海洋性气团的影响. 因此在雪坑样 品所代表的时段内, 小冬克玛底冰川中检测到的有 机污染物源自西风环流途径的中亚及我国西北干早 区. 玉珠峰冰川和七一冰川都处于高原东北部, 而且 玉珠峰冰川周围海拔高, 冬春季环境温度很低, 不利 于污染物的扩散，使污染物在原地积累。七一 

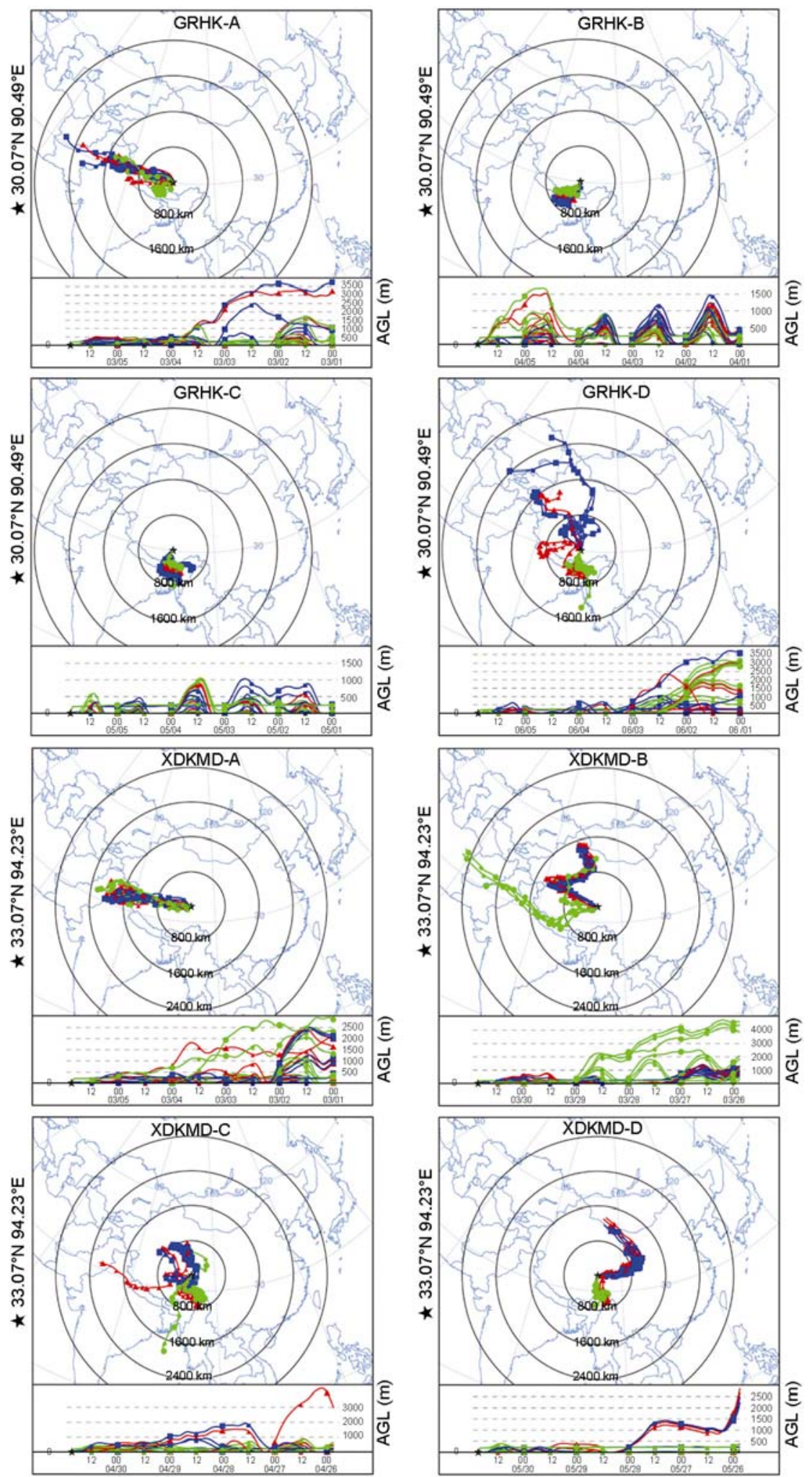

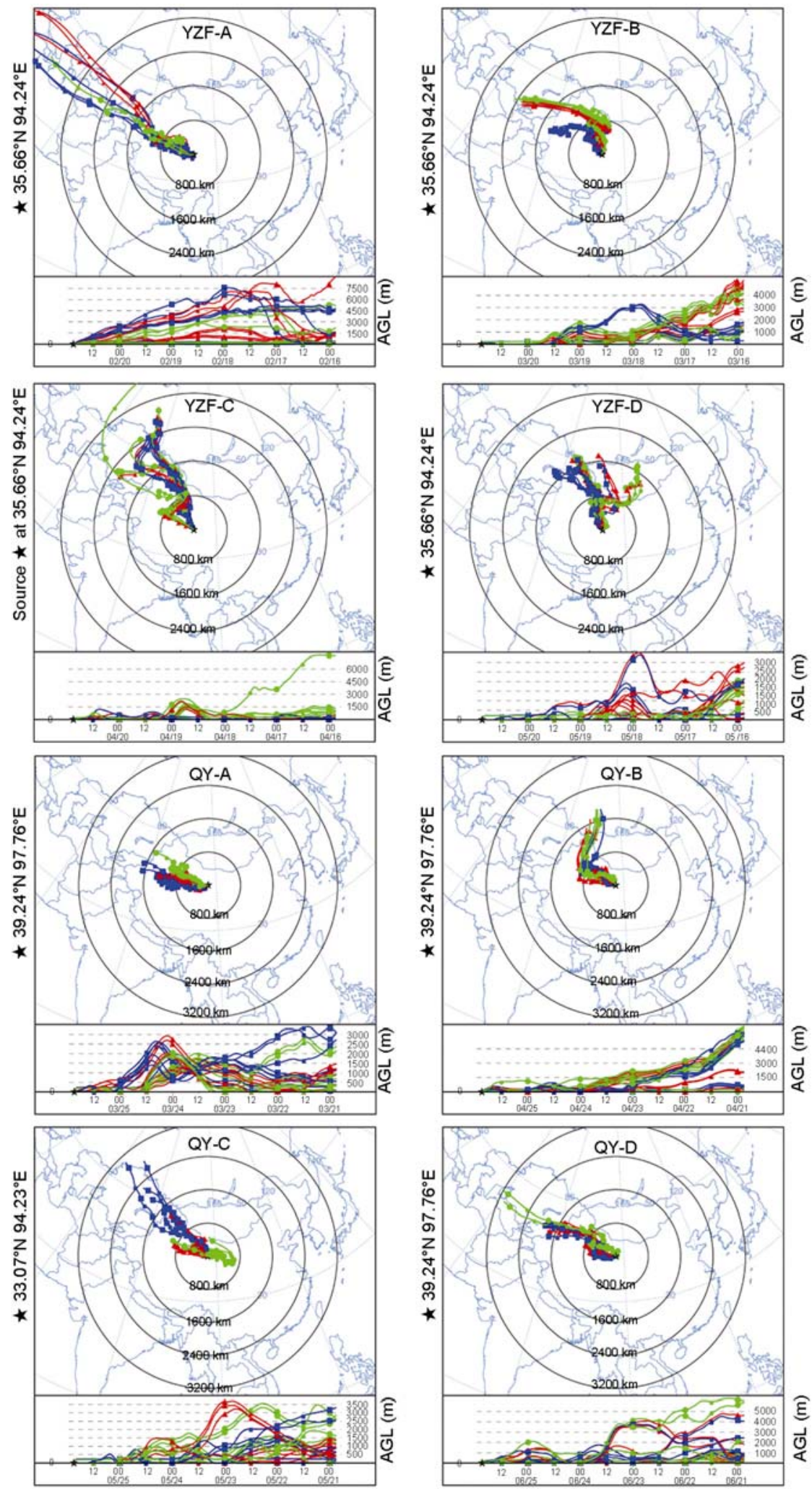

图 7 气团反向轨迹示意图

GRHK-A D 依次为: 古仁河口冰川 2008 年 3 月 1 5 日, 4 月 1 5 日, 5 月 1 5 日, 6 月 1 5 日; XDKMD-A D 依次为: 小冬克 玛底冰川 2008 年 3 月 1 5 日, 3 月 26 30 日, 4 月 26 30日, 5 月 26 30日;

YZF-A D 依次为: 玉珠峰冰川 2008 年 2 月 16 20日, 3 月 16 20日, 4 月 16 20日, 5 月 16 20 日; QY-A D 依次为: 七一冰 川2008年3月21 25日, 4 月 21 25日, 5 月 $21 \sim 25$ 日, 6 月 $21 \sim 25$ 日 
冰川的水汽主要来自西北方向, 可能来源于附近的 内陆蒸发或干燥的西风气流在经过相对温暖水体时 的快速蒸发, 由季风带来的水汽较少. 图 7 中 YZF-A D 和 QY-A D 表明玉珠峰冰川和七一冰川的 气团在雪坑样品所代表的时段内也来自中亚及西北 干旱区. 总之, 虽然古仁河口冰川和小冬克玛底冰川 都受到了海洋性水汽来源的影响, 但这两条冰川和 玉珠峰冰川以及七一冰川一样, 雪坑代表时段内冰 雪中的有机污染物主要源自西风环流途径的中亚及 我国西北干旱区.

\section{4 结论}

本研究在青藏高原 4 条典型冰川雪冰中检测了 美国环保署规定的 16 种优控多环芳烃. 结果表明,
多环芳烃的含量在玉珠峰冰川中最高, 小冬克玛底 冰川中最低, 七一冰川高于古仁河口冰川. 4 条冰川 雪冰中的多环芳烃主要以 2 4 环低分子量的化合物 为主, 而且都以菲的含量最高, 再结合多环芳烃的特 征比值和因子分析, 说明青藏高原地区冰川中的多 环芳烃主要来自煤和生物质的低温燃烧, 机车尾气 也贡献了部分多环芳烃. 气团轨迹示意图表明, 这 4 条冰川雪坑代表时段内雪冰中的有机污染物主 要源自西风环流途径的中亚及我国西北干旱区. 通 过对青藏高原不同区域冰川雪冰中多环芳烃的含量 研究, 我们可以及时地对其已经或将要带来的环境 污染做出相应的防止措施. 同时还可以认识到人类 活动在雪冰中所留下的污染痕迹, 从而探讨雪冰中 的有机污染物与环境生态、气候变化和人类活动的关 系.

\section{参考文献}

1 Olivella M A, Ribalta T G, de Febrer A R, et al. Distribution of polycyclic aromatic hydrocarbons in riverine waters after Mediterranean forest fires. Sci Total Environ, 2006, 355: 156-166

2 Ribes A, Grimalt J O, Garcia C J T, et al. Polycyclic aromatic hydrocarbons in mountain soils of the subtropical Atlantic. J Environ Qual, 2003, 32: 977-987

3 Wilson S C, Jones K C. Bioremediation of soil contaminated with polynuclear aromatic hydrocarbons (PAHs): A review. Environ Pollut, 1993, 81: 229-249

4 Bake S O, Field R A, Goldstone M E, et al. A review of atmospheric polycyclic aromatic hydrocarbons: Sources, fate and behavior. Water Air Soil Pollut, 1991, 60: 279-300

5 Simoneit B R T. A review of biomarker compounds as source indicators and tracers for air pollution. Environ Sci Pollut Res, 1999, 6: 159169

6 Garban B, Blanchoud H, Motelay-Massei A, et al. Atmospheric bulk deposition of PAHs onto France: Trends from urban to remote sites. Atmos Environ, 2002, 36: 5395-5403

7 Vehviläinen J, Isaksson E, Moore J C, et al. A 20th-century record of naphthalene in an ice core from Svalbard. Ann Glaciol, 2002, 35: 257 $-260$

8 Van Meter P C, Mahler B J, Furlong E T. Urban sprawl leaves its PAH signature. Environ Sci Technol, 2000, 34: 4064-4070

9 Chen B, Xuan X, Zhu L, et al. Distributions of polycyclic aromatic hydrocarbons in surface waters, sediments and soils of Hangzhou city, China. Water Res, 2004, 38: 3558-3568

10 Yang X Y, Okada Y, Tang N, et al. Long range transport of polycyclic aromatic hydrocarbons from China to Japan. Atmos Environ, 2007, 41: $2701-2718$

11 Sanders M, Sivertsen S, Scott G. Origin and distribution of polycyclic aromatic hydrocarbons in surficial sediments from the Savannah River. Arch Environ Contam Toxicol, 2002, 43: 438-448

12 Savinov V M, Savinova T N, Matishov G G, et al. Polycyclic aromatic hydrocarbons (PAHs) and organochlorines (OCs) in bottom sediments of the Guba Pechenga, Barents Sea, Russia. Sci Total Environ, 2003, 306: 39-56

13 Tao S, Cui Y H, Xu F L, et al. Polycyclic aromatic hydrocarbons(PAHs) in agricultural soil and vegetables from Tianjin. Sci Total Environ, 
2004, 320: 11-24

14 Honda K, Mizukami M, Ueda Y, et al. Residue level of polycyclic aromatic hydrocarbons in Japanese paddy soils from 1959 to 2002. Chemosphere, 2007, 68: 1763-1771

15 Wania F, Hoff J T, Jia C Q, et al. The effects of snow and ice on the environmental behavior of hydrophobic organic chemicals. Environ Pollut, 1998, 102: 25-41

16 Meyer T, Wania F. Organic contaminant amplification during snowmelt. Water Res, 2008, 42: 1847-1865

17 Carrera G, Fernandez P, Vilanova R M, et al. Persistent organic pollutants in snow from European high mountain areas. Atmos Environ, 2001, 35: 245-254

18 Nemirovskaya I A, Organic compounds in the snow-ice cover of eastern Antarctica. Geochem Int, 2006, 44: 825-834

19 Jaffrezo J L, Masclet P, Clain M P, et al. Transfer function of polycyclic aromatic hydrocarbons from the atmosphere to the polar ice. I: Determination of atmospheric concentrations at dye 3, Greenland. Atmos Environ, 1993, 27A: 2781—2785

20 Loewen M D, Sharma S, Tomy G, et al. Long range atmospheric transport and deposition of persistent organic pollutants and mercury in the Himalaya. Aquat Eco Heal Mana, 2005, 8: 223-233

21 Wang X P, Yao T D, WangP L, et al. The recent deposition of persistent organic pollutants and mercury to the Dasuopu glaciers, Mt. Xixiabangma, central Himalayas. Sci Total Environ, 2008, 394: 134-143

22 Wang X P, Xu B Q, Kang S C, et al. The historical residue trends of DDT, hexachlorocyclohexanes and polycyclic aromatic hydrocarbons in an ice core from Mt. Everest, central Himalayas, China. Atmos Environ, 2008, 42: 6699-6709

23 王小萍, 姚檀栋, 从志远, 等. 珠穆朗玛峰地区土壤和植被中多环芳烃的含量及海拔梯度分布. 科学通报, 2006, 51: 2517一-2525

24 Welch H E, Muir D C G, Billeck B N, et al. Brown snow: A long-range transport event in the Canadian Arctic. Environ Sci Technol, 1991, 25: $280-286$

25 Jaffrezo J L, Clain M P, Masclet P, et al. Polycyclic aromatic hydrocarbons in the polar ice of Greenland, geochemical use of these atmospheric tracers. Atmos Environ, 1994, 28: 1139-1145

26 Kawamura K, Suzuki I, Fuji Y, et al. Ice core record of polycyclic aromatic hydrocarbons over the past 400 years. Naturwissenschaften, 1994, 81: 502-505

27 Bodnár E, Hlavay J. Atmospheric deposition of polycyclic aromatic hydrocarbons on the Lake Balaton, Hungary. Microchem J, 2005, 79: $213-220$

28 Mille G, Asia L, Guiliano M, et al. Hydrocarbons in coastal sediments from the mediterranean sea (Gulf of Fos area, France). Mar Pollut Bull, 2007, 54: 566-575

29 Franz T P, Eisenreich S J. Snow scavenging of polychlorinated biphenyls and polycyclic aromatic hydrocarbons in Minnesota. Environ Sci Technol, 1998, 32: 1771-1778

30 Su Y, Lei Y D, Wania F, et al. Regressing gas/particle partitioning data for polycyclic aromatic hydrocarbons. Environ Sci Technol, 2006, 40: $3558-3564$

31 Daly G L, Wania F. Organic contaminants in mountains. Environ Sci Technol, 2005, 39: 385-398

32 Peters A J, Gregor D J, Teixeira C, et al. The recent depositional trend of polycyclic aromatic hydrocarbons and elemental carbon to the Agassiz Ice Cap, Ellesmere Island, Canada. Sci Total Environ, 1995, 160/161: 167-179

33 Wang X P, Yao T D, Cong Z Y. Gradient distribution of persistent organic contaminants along northern slope of central-Himalayas, China. Sci Total Environ, 2006, 372: 193-202

34 Liu X, Zhang G, Jones K C, et al. Compositional fractionation of polycyclic aromatic hydrocarbons (PAHs) in mosses (Hypnum plumaeformae WILS.) from the northern slope of Nanling Mountains, South China. Atmos Environ, 2005, 39: 5490 - 5499

35 Guinan J, Charlesworth M, Service M, et al. Sources and geochemical constraints of polycyclic aromatic hydrocarbons (PAHs) in sediments and mussels of two Northern Irish Sea-loughs. Mar Pollut Bull, 2001, 42: 1073-1081

36 Lee M L, Prado G P, Howard J B, et al. Source identification of urban airborne polycyclic aromatic hydrocarbons by chromatographic mass spectrometry and high resolution mass spectrometry. Biomed Mass Spectrom, 1977, 4: 182-185

37 Yunker M B, Macdonald R W, Vingarzan R, et al. PAHs in the Fraser River basin: A critical appraisal of PAH ratios as indicators of PAH source and composition. Org Geochem, 2002, 32: 489-515

38 李全莲, 王宁练, 武小波, 等. 青藏高原雪冰中正构烷烃的组成特征及其环境意义. 中国科学 D 辑: 地球科学, 2009, 39: 1279-1287

39 Grimmer G, Jacob J, Naujack K W, et al. Profile of the polycyclic aromatic compounds from crude oils-inventory by GC, GC -MS. PAH in environmental Materials: Part 3, Fresenius. Analyt Chem, 1983, 316: 29-36 
40 Masclet P, Hoyau V, Jaffrezo J L, et al. Polycyclic aromatic hydrocarbon deposition on the ice sheet of Greenland. Part I: Superficial snow. Atmos Environ, 2000, 34: 3195-3207

41 Mai B X, Qi S H, Zeng E Y, et al. Distribution of polycyclic aromatic hydrocarbons in the coastal region off Macao, China: Assessment of input sources and transport pathways using compositional analysis. Environ Sci Technol, 2003, 37: 4855-4863

42 Mastral A M, Callén M, Murillo R. Assessment of PAH emissions as a function of coal combustion variables. Fuel, 1996, 75: 1533-1536

43 Khalili N R, Scheff P A, Holsen T M. PAH source fingerprints for coke ovens, diesel and gasoline engines, highway tunnels, and wood combustion emissions. Atmos Environ, 1995, 29: 533-542

44 Simcik M F, Eisenreich S J, Lioy P J. Source apportionment and source/sink relationships of PAHs in the coastal atmosphere of Chicago and Lake Michigan. Atmos Environ, 1999, 33: 5071—5079

45 田立德, 姚檀栋, 孙维贞, 等. 青藏高原南北降水中 $\delta \mathrm{D}$ 和 $\delta^{18} \mathrm{O}$ 关系及水汽循环. 中国科学 $\mathrm{D}$ 辑: 地球科学, 2001, 31: 214一220 